\title{
DISEÑO DE UN PROGRAMA DE ORIENTACIÓN ACADÉMICA Y PROFESIONAL PARA LAS MUJERES EN RIESGO DE EXCLUSIÓN SOCIAL
}

\author{
Rufino Cano González \\ Universidad de Valladolid
}

\begin{abstract}
RESUMEN. Aunque el tema no es nuevo, sin embargo, hoy, iniciado ya el siglo XXI, el problema no solo no ha desaparecido, sino que ante la falta de alternativas serias de cambio, ha experimentado un fuerte y notable incremento. Los gobiernos y las administraciones no se atreven o no quieren hablar de esta problemática y prefieren mantener una actitud ambigua a la hora de ofertar salidas de distinto tipo. Creemos imprescindible profundizar en el debate teórico sobre esta temática, escuchar a sus protagonistas y avanzar en políticas públicas que promuevan para este colectivo, empezando por las mujeres pobres, alternativas laborales, económicas, sociales y de cambio de vida. En consecuencia se hace necesario desarrollar programas de bienestar social que hagan frente a la pobreza y al desempleo favoreciendo, de esta manera, el cambio que reclama una proporción significativa de trabajadoras implicadas en esta ocupación. Nuestra oferta, ciertamente enriquecida con otro tipo de acciones dirigidas a los fundamentos económicos y sociales que sostienen este tipo de estructuras, apuesta por el desarrollo de Programas de Orientación Académica y Profesional que permitan a este colectivo de riesgo cambiar de ocupación e integrarse social y laboralmente en la comunidad de los ciudadanos/as.
\end{abstract}

ABSTRACT. Despide being an old matter, once begun the XXI century, not only has not the problem despaired, but also it has increased due to a lack of alternatives. Governments and Administrations do not dare or they do not want to talk about the matter and prefer to maintain a ambiguous attitude when offering different type of solutions. We believe thatch it is absolutely necessary to go deeper into theoretical debate, listen to the main characters and go forward in public policies which promote alternatives, for their poverty, labor, economic, social and change of life for these women. Subsequently, it is necessary to develop social welfare programmers, which can remedy poverty and unemployment, essential in order to satisfy the demand of these work ring women. Our offer, enriched by other type of actions towards economic and social foundations, basing these structures, supports a development of vocational and educational guidance in order to make easier for these women to go out and integrate themselves in a social and labor community of citizens.

\section{Introducción}

El negocio de la prostitución, tema de debate vigente en todo el mundo en el movimiento de mujeres, es, actualmente, uno de los más lucrativos, incluso mucho más que el tráfico de drogas. Según estadísticas elaboradas por el Instituto de la Mujer, a 
partir de unos datos ciertamente difíciles de cuantificar por distintas razones que intuye el lector, en España se prostituyen alrededor de 300.000 mujeres en un sinfín de lugares distintos (salones de masaje, clubes, clubes de carretera, la propia calle, saunas, discotecas, bares, cabarets, líneas eróticas, sexo virtual, internet, pensiones, hoteles pisos, anuncios en prensa, películas, videos, etc.). En consecuencia, las posibilidades para trabajar dentro de esta industria (es una forma más de esclavitud) son muchas, especialmente para las personas inmigrantes sin papeles que, en situación de ilegalidad y clandestinidad, entran en nuestro país previo pago del billete a la mafia de turno que las ha traído y, posteriormente, distribuirá por toda la geografía con el fin de trabajar como prostitutas. El tema no es nuevo, ya que en el siglo pasado existieron numerosas organizaciones feministas en distintos países del mundo luchando contra la denominada, en aquel entonces, "trata de blancas" y las organizaciones mafiosas que las promovían. Sin embargo, hoy, en el inicio del siglo XXI, el problema no ha desaparecido, sino que más bien se ha recrudecido. A pesar de todo, ningún país parece contar con una legislación clara, ni con políticas públicas eficaces ni, mucho menos, con programas para abordar el problema que estamos comentando como un fenómeno universal con numerosos añadidos concomitantes.

La difícil situación en que se encuentra la mujer prostituta puede conducirle a su exclusión del proceso de formación-ocupación. Dado que la mayoría de estas personas tienen escasos niveles culturales, académicos y formativos, esa formación académica y cultural se hace absolutamente necesaria para abrir nuevas vías de reinserción laboral. Es evidente que el primer paso a dar (además de la lucha contra las redes) sería brindarles una salida integradora para que puedan abandonar la prostitución, si así lo desean, y tengan la posibilidad de poder acceder a un trabajo digno. Por ello, nuestro propósito no es, solamente, conseguir que esta profesión o, mejor dicho, que este trabajo al que se ven obligadas a recurrir miles de mujeres en un mundo cada día más globalizado y sin fronteras para sobrevivir malamente, sea considerado como una forma de violencia de género y que, como tal violencia se denuncie ante la justicia y se apueste por su total eliminación de la sociedad (aun cuando esto sea utópico), sino, también y muy especialmente, mejorar su nivel educativo y cultural a través de la puesta en funcionamiento de distintos programas, fundamentalmente, de desarrollo personal, de desarrollo del bienestar social y de orientación profesional, que hagan frente a la pobreza, el desempleo y las obligaciones familiares, abran nuevas perspectivas y posibilidades reales de inserción laboral a este colectivo de mujeres, en situación de riesgo permanente, sobre todo, a las más pobres que cada vez recurren con mayor frecuencia al ejercicio de la prostitución como medio de vida ante la falta de alternativas laborales y económicas.

Por todas estas razones y porque el marco de intervención de la Orientación Psicopedagógica, de cara a la formación de los futuros Orientadores (licenciados en Psicopedagogía) en nuestras Facultades de Educación, asume un amplio escenario de mediación, cada vez más complejo, que avanza no solamente hacia adelante, hacia el futuro, sino, también, hacia los lados como las ondas que producen las piedras arrojadas en un estanque, creemos necesario abordar una de sus posibles áreas o temáticas de conocimiento y de intervención, en tanto que aspectos esenciales a considerar en dicha formación, como es el caso de la atención a las necesidades educativas espe- 
ciales que en esta última década se ha ido ampliando hasta incluir una compleja diversidad de casuísticas entre las que se encuentran grupos de riesgo (cuestión que nos ocupa en este artículo), marginados, minorías étnicas, grupos desfavorecidos, inmigrantes, etc. Desde esta perspectiva se habla, hoy más que nunca, de la atención a la diversidad como uno de los ámbitos temáticos o centros de interés de la Orientación Psicopedagógica en contextos no necesariamente institucionales donde el orientado, como ciudadano, recibe la ayuda que necesita de los medios comunitarios, sin que esto exima otro tipo de ayudas prestadas desde el propio sistema educativo.

En consecuencia, la Orientación Psicopedagógica, en sus facetas preventiva, terapéutica y de desarrollo personal, encuentra en la atención a este colectivo de personas, uno de sus campos de intervención inmediata más demandados y urgentes al que hay que prestar todo el apoyo profesional, social y educativo fundamentalmente, amén de otros servicios y atenciones de carácter complementario e igualmente necesarios. Serán, pues, los Orientadores junto con otros profesionales de la educación y la asistencia social quienes, a través del desarrollo de programas de asesoramiento y ayuda especializada, presten el apoyo necesario que implícitamente demandan estos colectivos o grupos sociales de alto riesgo, con la esperanza que desde la acción teórico-formativa y desde la práctica-educativa formal e informal vayan mejorando, desarrollando y profundizando con sus diferentes aportaciones las problemáticas que impiden el desarrollo integral de los individuos que las padecen.

\section{Diseño del modelo: fases}

Nuestra propuesta de intervención se inicia con el diseño y desarrollo de un modelo de Orientación Profesional, que en este momento estamos aplicando con alumnos de $5^{\circ}$ de Psicopedagogía (durante su periodo de prácticas), supervisado por el profesor Cano González en el que destacamos una serie de fases que, a continuación, pasamos a comentar, siquiera, brevemente.

\subsection{Fase I: EXPLORACIÓN}

Se trata de analizar la situación del mercado de trabajo y las posibilidades formativas del medio. Respecto del análisis de la situación del mercado de trabajo en relación al sector demandante mujer, hay que destacar que en nuestro país, actualmente, existe una discriminación segregacional en el empleo que se manifiesta en los grupos profesionales que éstas ocupan (el $80 \%$ trabaja en el sector servicios) y en el desajuste existente en la composición por sexos de la oferta efectiva de trabajo debido a factores socio-familiares, culturales y económicos. Por esto, es necesario estructurar políticas de formación descentralizadas que faciliten la creación de talleres de especialización laborales, cuyo objetivo sea la preparación de sus participantes en aquellos oficios que les permita, de forma efectiva y real, el acceso al mercado de trabajo. En consecuencia, se hace imprescindible atender, no sólo y únicamente a cuestiones relacionadas con la formación profesional que necesitan sino, también, y muy especialmente, prestar atención a aspectos de su desarrollo personal y social, a la vez que establecer un plan estructurado para el seguimiento de su inserción laboral. 


\subsection{Fase II: DIAGNÓSTICO}

En esta fase pretendemos estudiar el perfil profesional y personal del sujeto al que va dirigida la propuesta de orientación. Para ello, hemos recogido las conclusiones más importantes señaladas en el estudio llevado a cabo por la Junta de Castilla y León en 1998, relacionado con la prostitución femenina en dicha comunidad, por cuanto creemos es bastante representativo de lo que ocurre en el resto del país. Dichas conclusiones señalan:

1ํ. Cada 1000 mujeres residentes en Castilla-León, 1'96 se dedican a la prostitución. De ellas sólo un $24 \%$ son castellano-leonesas, mientras que el $41 \%$ son extranjeras.

2 ㅇ. La media de edad de las prostitutas que ejercen en esta comunidad es de 30 años. De forma general, se puede afirmar que la mayoría inician su actividad alrededor de los 20 años y la mantienen hasta los 40 . Asimismo, más de la mitad trabajan en locales y no disponen de ningún tipo de cobertura sanitaria. Las prostitutas que ejercen en la calle, lo hacen en condiciones de higiene lamentables; la mayoría son toxicómanas y realizan exclusivamente el número de servicios necesarios para adquirir la dosis; sus tarifas son muy bajas.

3 ‥ El prototipo de prostituta en esta comunidad corresponde al de una mujer soltera que procede del entorno urbano, tendiendo a ejercer lejos de su lugar de origen. Tiene una media de 2 hijos; su horario laboral, la ausencia de vivienda propia y la falta de apoyo de un padre que les proporcione ayuda, le lleva al relativo abandono de sus hijos, encomendando su cuidado a familiares.

$4^{\circ}$. Buena parte de ellas pertenecen a redes organizadas que las someten a órdenes estrictas de trabajo. Su estado de ilegalidad y el temor a represalias les impide acudir a la justicia.

5‥ El $20 \%$ son analfabetas; un $40 \%$ posee estudios primarios, y los estudios universitarios apenas tienen presencia en este sector de población.

6 o. Su situación laboral previa a la prostitución ha sido el paro o actividades profesionales de baja cualificación. Las prostitutas manifiestan una autoestima muy baja a la hora de afrontar una posible alternativa profesional diferente a la prostitución.

$7^{\circ}$. Son mujeres procedentes de estatus sociales bajos y alguna de ellas ha tenido familiares dedicados a la prostitución. Son las razones económicas la causa fundamental de su entrada y permanencia en la prostitución.

$8^{\circ}$. Los clientes habituales suelen ser hombres casados de 36 a 50 años y de clase media.

9o. La situación económica de la prostituta está en relación directa con el número y coste de los servicios que realiza, siendo la media unas 5500 pesetas. Su nivel de ingresos no es bajo.

$10^{\circ}$. Hay que destacar que la prostitución ha generado en Castilla-León alrededor de 5.130 millones de pesetas, durante el año de 1998. 


\subsection{Fase III: RELACIÓN}

Se trata de relacionar el perfil profesional con las posibilidades de formación y el mercado laboral, con el fin de mejorar el nivel educativo y cultural de este colectivo de mujeres, haciendo hincapié en el desarrollo de unas buenas habilidades sociales y de una adecuada orientación para la búsqueda de empleo, teniendo como meta formativa, siempre que sea posible, la obtención del Graduado Escolar o el Graduado en Educación Secundaria.

\subsection{Fase IV: DECISIÓN.}

Esta fase se relaciona directamente con las fases anteriores, de tal manera que, en función de la evaluación obtenida por el sujeto en dichas fases, se opta o no por ampliar la formación o pasar directamente a la búsqueda de empleo. Esta necesaria optatividad, nos conduce directamente a la fase siguiente.

\subsection{Fase V: FORMACIÓN.}

Partimos de una formación base, como es el Graduado Escolar o el Graduado en Educación Secundaria, para pasar, primero, a un entrenamiento en la adquisición y desarrollo de habilidades sociales y de la vida diaria que consideramos son de gran relevancia en las relaciones laborales y, segundo, a un dominio de las técnicas de búsqueda de empleo que capacite a las mujeres para encontrar un trabajo estable y ajustado a sus posibilidades.

\subsection{Fase VI :TRÁNSITO AL EMPLEO.}

Como culminación de todas las fases anteriores, lo deseable sería la inserción laboral de este colectivo de mujeres, para lo cual estableceríamos un plan de seguimiento de duración variable, según cada caso.

\section{El programa de formación.}

\subsection{Objetivos del programa:}

\subsubsection{Objetivos generales:}

- Desarrollar acciones que recojan la necesidad de inserción social de la mujer prostituta.

- Contemplar la integración social como vía para el acceso a los derechos sociales y la participación en la vida comunitaria desde posiciones más igualitarias.

- Trabajar los condicionamientos personales, familiares o ambientales que están en el origen de su posición de exclusión social.

- Posibilitar una formación previa de mejora de sus aptitudes generales orientándolas, profesionalmente, para la inserción laboral no marginal. 
- Adquirir los conocimientos básicos para la obtención del Graduado, elevando su nivel cultural.

- Apoyar la adquisición de hábitos de trabajo (horarios, permanencia, responsabilidad...).

- Facilitar orientación para dar a conocer los recursos laborales y formativos de la comunidad.

- Fomentar la autoestima individual para lograr una mayor autonomía en su vida social y laboral.

\subsubsection{Objetivos específicos:}

\begin{tabular}{|c|c|c|}
\hline FORMACIÓN BÁSICA & HABILIDADES SOCIALES & BÚSQUEDA DE EMPLEO \\
\hline $\begin{array}{l}\text { Adquirir los conocimien- } \\
\text { tos básicos para la obten- } \\
\text { ción del Graduado Escolar } \\
\text { o Graduado en Educación } \\
\text { Secundaria. } \\
\text { - Elevar se nivel cultural. } \\
\text { - Facilitar la obtención de la } \\
\text { titulación básica. } \\
\text { - Apoyar la adquisición de } \\
\text { hábitos de trabajo (hora- } \\
\text { rios, permanencia, respon- } \\
\text { sabilidad). } \\
\text { - Facilitar orientación a lo } \\
\text { largo del proceso para dar } \\
\text { a conocer los recursos } \\
\text { laborales y formativos exis- } \\
\text { tentes en la comunidad. } \\
\text { - Fomentar la autoestima } \\
\text { individual para lograr una } \\
\text { mayor autonomía en su } \\
\text { vida social y laboral. }\end{array}$ & $\begin{array}{l}\text { Adquirir y disponer las } \\
\text { conductas de interacción } \\
\text { básicas necesarias para } \\
\text { interactuar con otras per- } \\
\text { sonas en el contexto social } \\
\text { cotidiano. } \\
\text { Aprender a desarrollar y } \\
\text { mantener relaciones posi- } \\
\text { tivas y satisfactorias con } \\
\text { los iguales. } \\
\text { Aprender a ser asertivo y } \\
\text { expresar emociones, afecto } \\
\text { y opiniones, recibiendo las } \\
\text { demás adecuadamente. } \\
\text { Enseñar a solucionar, de } \\
\text { forma constructiva y posi- } \\
\text { tiva, los problemas inter- } \\
\text { personales que se les } \\
\text { plantea en su relación con } \\
\text { otras personas. }\end{array}$ & $\begin{array}{l}\text { Fomentar el desarrollo de } \\
\text { pautas de análisis de sus } \\
\text { propias capacidades, limi- } \\
\text { taciones e intereses profe- } \\
\text { sionales. } \\
\text { - Potenciar la fijación de } \\
\text { metas con relación a la } \\
\text { búsqueda de posibles } \\
\text { empleos. } \\
\text { - Informar de los cauces y } \\
\text { técnicas de búsqueda de } \\
\text { empleo. } \\
\text { - Apoyar la adquisición de } \\
\text { hábitos de trabajo (hora- } \\
\text { rios, responsabilidad y } \\
\text { permanencia) y del } \\
\text { empleo del tiempo libre. } \\
\text { - Posibilitar una cualifica- } \\
\text { ción laboral. } \\
\text { Crear una red de informa- } \\
\text { ción para dar a conocer } \\
\text { los recursos laborales y } \\
\text { formativos existentes en la } \\
\text { comunidad. }\end{array}$ \\
\hline
\end{tabular}




\subsection{Formación Básica.}

\subsubsection{Graduado Escolar o Graduado en Educación Secundaria}

3.2.1.1. Contenidos:

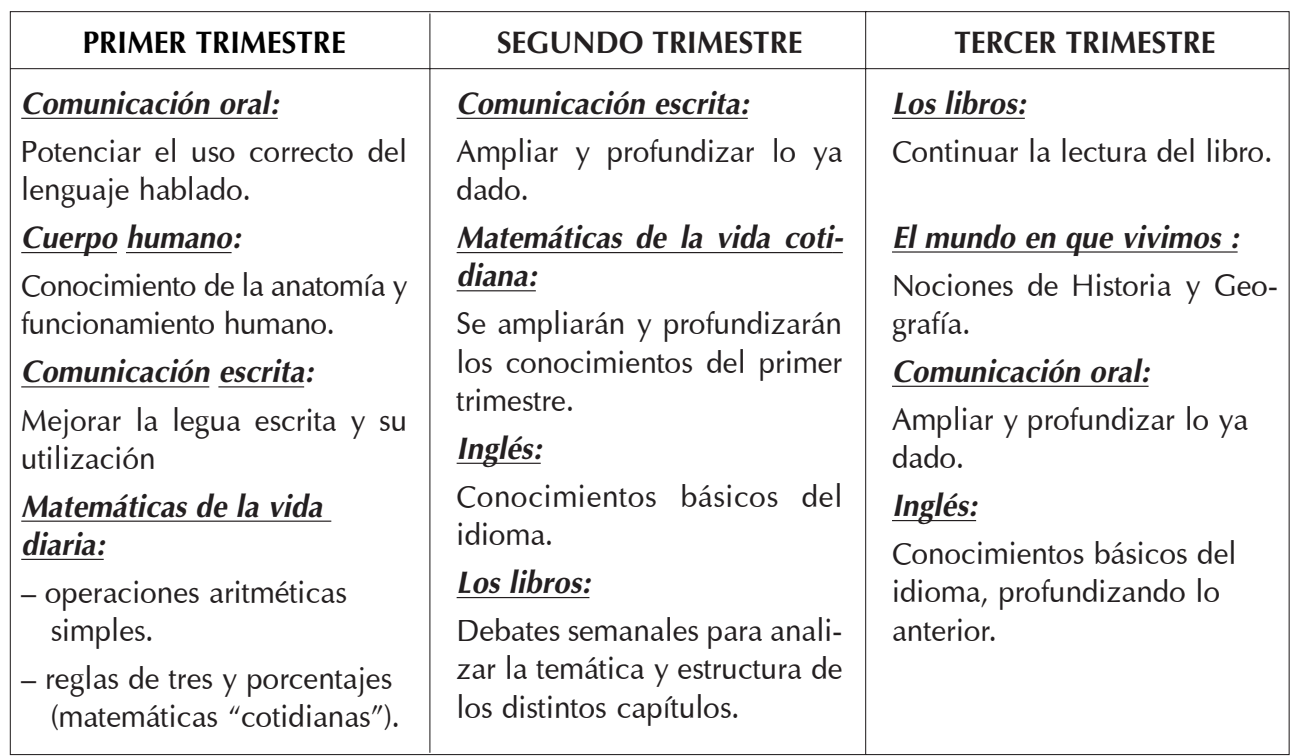

\subsubsection{Metodología:}

La metodología a seguir será eminentemente activa y participativa, de tal manera que tras una breve explicación general por parte del profesor, el grupo de mujeres completará el desarrollo del tema siguiendo los criterios que fundamentan la adquisición del aprendizaje a través de la investigación. Siempre que el momento lo requiera, la atención se hará tan individualizada como demande cada caso en particular. No hemos de perder de vista que el punto central de este tipo de metodología ha de ser la motivación: "el que lo intenta lo consigue".

Al finalizar cada unidad se hará una puesta en común de los logros alcanzados y, también, las dificultades que, tanto a alumnos como a profesores, hemos ido encontrando, al objeto de adelantar posibles soluciones a problemas actuales y, tal vez, futuros. Esto nos ayudará a formar un grupo más unido y a superar, con éxito, las distintas problemáticas que vayan surgiendo a lo largo del proceso formativo.

\subsubsection{Recursos:}

- Material curricular elaborado por el orientador y el equipo educativo en relación al temario marcado por el MEC con vistas a superación de los exámenes libres de Graduado Escolar.

- Material didáctico: mapas, fotocopias, folios, lapiceros, bolígrafos, gomas, pizarra, fotografías, recortes de la prensa, revistas, folletos del INEM, vídeos y películas. 


\subsubsection{Evaluación:}

La evaluación se basará en la observación continuada de cada persona. Se tendrá en cuenta, sobre todo, su grado de atención y participación, su progreso y su esfuerzo. Además, se realizará una evaluación al término de cada módulo en la que nos fijaremos tanto en el nivel de conocimientos adquiridos como en el grado de aproximación a los objetivos planteados. Esta evaluación se completará con la presentación de diversos trabajos propuestos por los profesores.

\subsubsection{Búsqueda de empleo:}

\subsubsection{Entrenamiento en Habilidades Sociales:}

Para abordar el entrenamiento de las habilidades sociales, nos hemos guiado por el programa de Goldstein (1989). De él hemos seleccionado aquellas que consideramos necesarias y fundamentales para la inserción del colectivo de referencia en el mundo laboral. Como acción de referencia inicial y, a la vez, complementaria, recomendamos aplicar el "Cuestionario de Habilidades de Aprendizaje Estructurado", inserto en el mismo programa y que consta de seis bloques de habilidades:

\begin{tabular}{|l|l|}
\hline - Primeras habilidades sociales. & - Habilidades alternativas a la agresión. \\
\hline - Habilidades sociales avanzadas. & - Habilidades para hacer frente al estrés. \\
\hline - Habilidades relacionas con los sentimientos. & - Habilidades de planificación. \\
\hline
\end{tabular}

Las sesiones se estructuran siempre siguiendo los mismos pasos; lo único que cambian son las ejemplificaciones de las tareas que, en cada caso, serán las específicas de la habilidad. Así, pues, la secuencia de pasos en cada sesión corresponde al siguiente cliché:

A). Información conceptual: Instrucción verbal, diálogo y discusión.

a) Delimitación y especificación de la habilidad: el orientador intenta que las alumnas comprendan el significado de la habilidad a través de ejemplos cotidianos.

b) Importancia y relevancia para el alumnado: se explicará la importancia de la habilidad utilizando preguntas sobre aspectos de la vida cotidiana.

c) Aplicación: se trata de descubrir la importancia de esta habilidad y la aplicación a su vida personal.

B). Componentes y pasos conductuales específicos de la habilidad.

C). Modelado

El orientador, ayudado por alguna alumna que posea la habilidad en cuestión, modela las conductas adecuadas para conseguirla. También se proponen ejemplos de tareas para que las alumnas las lleven a la práctica. Esta situación marca el punto de partida de la siguiente sesión. 
La metodología será siempre activa. La evaluación será continua, a través de preguntas del Orientador sobre aspectos y cuestiones de interés propios de la vida diaria. Con ello pretendemos valorar el nivel de competencia social de cada alumna. Para completar la evaluación, se establecerán actividades de feedback y refuerzo durante toda la sesión. Posteriormente, pasaremos a desarrollar cada una de las sesiones que conforman este programa, divididas según los bloques anteriormente señalados.

\subsubsection{Entrenamiento en técnicas de búsqueda de empleo:}

Para buscar empleo es necesario definir los objetivos profesionales propios, decidir lo que se quiere hacer, evaluar las necesidades personales y valorar las posibles dificultades.

Elaborar un proyecto profesional significa "definir los objetivos profesionales propios a partir del conocimiento de las propias potencialidades". Para ello, una vez que las alumnas han superado la propuesta de adquisición de las habilidades sociales básicas y ya disponen de una serie de herramientas para el desarrollo de su propio autoconcepto y acercamiento a los demás, es el momento de comenzar un nuevo programa que les facilite nuevas vías de actuación de cara a la búsqueda del empleo más adecuado.

Para la realización de este bloque nos hemos basado en el PLAN MABEM, editado por el Instituto de la Mujer (Ministerio de Asuntos Sociales, 1996).

El entrenamiento en la búsqueda de empleo consta de los siguientes pasos:

\begin{tabular}{|c|c|c|c|c|c|}
\hline $\begin{array}{c}\text { ¿Qué } \\
\text { quiero hacer? }\end{array}$ & $\begin{array}{c}\text { Entonces, } \\
\text { ¿qué debo hacer? }\end{array}$ & $\begin{array}{c}\text { Me pongo a } \\
\text { buscar empleo }\end{array}$ & $\begin{array}{c}\text { Continúo hasta } \\
\text { encontrarlo }\end{array}$ & $\begin{array}{c}\text { La Selección } \\
\text { En tu nuevo } \\
\text { trabajo }\end{array}$ \\
\hline
\end{tabular}

La metodología para cada una de estas sesiones será variable, dependiendo de la especificidad del tema, como se podrá observar en cada uno de los cuadros que presentamos. A continuación, pasamos a desarrollar los bloques de intervención que conforman los programas de "Habilidades sociales" y "Entrenamiento en búsqueda de empleo". 
PROGRAMA DE HABILIDADES SOCIALES

BLOQUE 1: "PRIMERAS HABILIDADES SOCIALES"

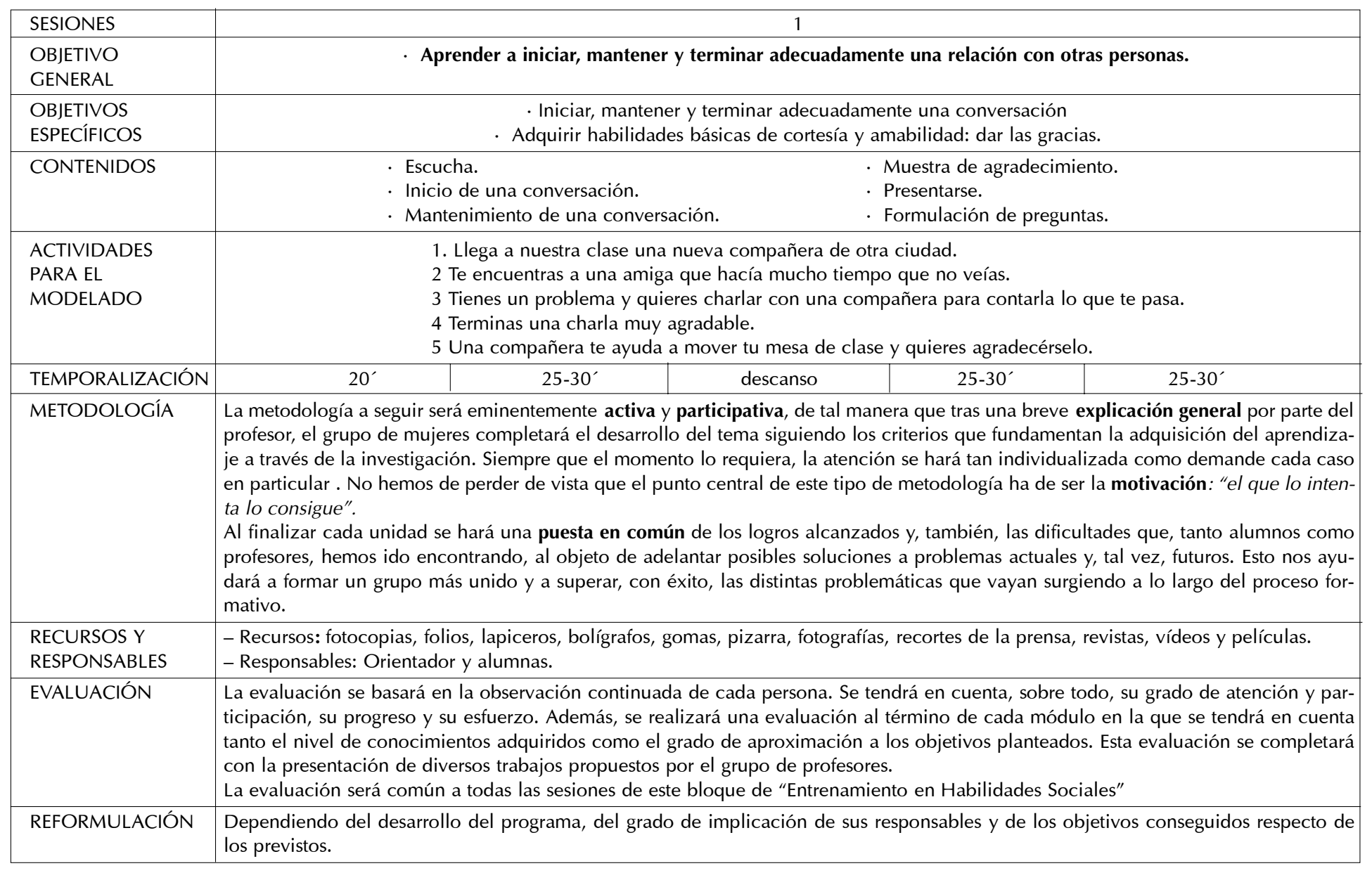




\section{BLOQUE 2: “HABILIDADES SOCIALES AVANZADAS"}

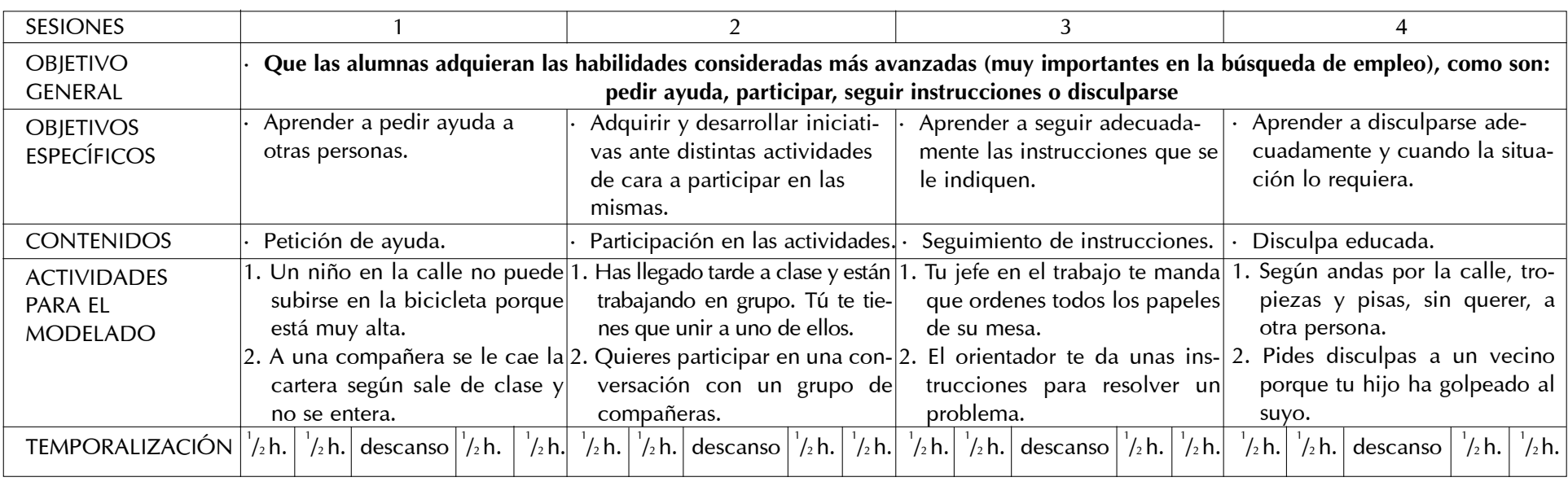

BLOQUE 3: "HABILIDADES RELACIONADAS CON LOS SENTIMIENTOS"

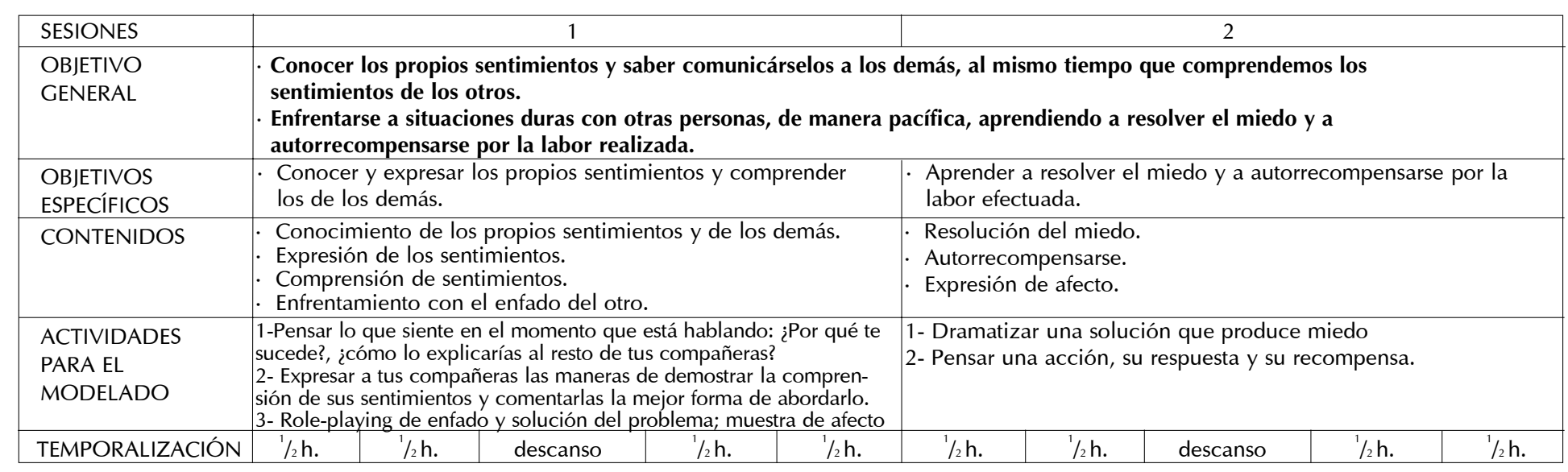


BLOQUE 4: "HABILIDADES ALTERNATIVAS A LA AGRESIÓN"

\begin{tabular}{|c|c|c|c|c|c|c|c|c|c|c|}
\hline SESIONES & \multicolumn{5}{|c|}{1} & \multicolumn{5}{|c|}{2} \\
\hline $\begin{array}{l}\text { OBJETIVO } \\
\text { GENERAL }\end{array}$ & \multicolumn{10}{|c|}{$\begin{array}{l}\text { Adquirir las habilidades básicas necesarias para la resolución de situaciones problemáticas a través de mecanismos diferentes a la } \\
\text { agresión: cooperación, ayuda, negociación, autocontrol, etc. }\end{array}$} \\
\hline $\begin{array}{l}\text { OBJETIVOS } \\
\text { ESPECÍFICOS }\end{array}$ & \multicolumn{5}{|c|}{$\begin{array}{l}\text { Establecer un clima de ayuda y cooperación adecuado a las } \\
\text { situaciones a las que se enfrenten. }\end{array}$} & \multicolumn{5}{|c|}{$\begin{array}{l}\text { - Usar el autocontrol para evitar posibles problemas con otras per- } \\
\text { sonas. }\end{array}$} \\
\hline CONTENIDOS & \multicolumn{5}{|c|}{$\begin{array}{l}\text { Ayuda a los demas } \\
\text { Cooperar y compartir }\end{array}$} & \multicolumn{5}{|c|}{$\begin{array}{l}\text { - Autocontrol. } \\
\text { Defensa de los propios derechos. Evitación de peleas/problemas }\end{array}$} \\
\hline $\begin{array}{l}\text { ACTIVIDADES } \\
\text { PARA EL } \\
\text { MODELADO }\end{array}$ & \multicolumn{5}{|c|}{$\begin{array}{l}\text { 1- Compartir algo propio con los demás. } \\
\text { 2- Ayudar a un compañero con problemas. }\end{array}$} & \multicolumn{5}{|c|}{$\begin{array}{l}\text { 1- Te autocontrolas cuando te cogen algo tuyo sin permiso. } \\
\text { 2- Alguien se te cuela en la cola de la compra. } \\
\text { 3- Arreglas adecuadamente una situación con la madre de otro niño } \\
\text { que le ha quitado el balón a tu hijo. }\end{array}$} \\
\hline TEMPORALIZACIÓN & $1 / 2 \mathrm{~h}$. & $1 / 2 \mathrm{~h}$. & descanso & $1 / 2 \mathrm{~h}$. & $1 / 2 \mathrm{~h}$. & $1 / 2 \mathrm{~h}$. & $1 / 2 \mathrm{~h}$. & descanso & $1 / 2 h$. & $1 / 2 \mathrm{~h}$. \\
\hline
\end{tabular}

BLOQUE 5: “HABILIDADES PARA HACER FRENTE AL ESTRÉS”

\begin{tabular}{|c|c|c|c|c|c|c|c|c|c|c|c|}
\hline SESIONES & \multicolumn{4}{|c|}{1} & \multicolumn{4}{|c|}{2} & \multicolumn{3}{|c|}{3} \\
\hline $\begin{array}{l}\text { OBJETIVO } \\
\text { GENERAL }\end{array}$ & \multicolumn{11}{|c|}{ Aprender a desarrollar y mantener relaciones positivas y satisfactorias con los iguales. } \\
\hline $\begin{array}{l}\text { OBJETIVOS } \\
\text { ESPECÍFICOS }\end{array}$ & \multicolumn{4}{|c|}{$\begin{array}{l}\text { - Aprender a formular una queja adecuada- } \\
\text { mente. } \\
\text { Aprender a responder a las quejas de los } \\
\text { demás. }\end{array}$} & \multicolumn{4}{|c|}{$\begin{array}{l}\text { Dotar de estrategias para vencer los sentimientos } \\
\text { de vergüenza. } \\
\text { Saber responder ante situaciones en las que uno se } \\
\text { ve discriminado. } \\
\text { Actuar en defensa de los otros para defender sus } \\
\text { derechos. }\end{array}$} & \multicolumn{3}{|c|}{$\begin{array}{l}\text { Dotar de estrategias y habilidades que per- } \\
\text { mita hacer frente a la presión del grupo. } \\
\text { Aprender a responder a las acusaciones } \\
\text { del grupo. }\end{array}$} \\
\hline CONTENIDOS & \multicolumn{4}{|c|}{$\begin{array}{l}\text { Formulación de quejas. } \\
\text { Respuesta a quejas. }\end{array}$} & \multicolumn{4}{|c|}{$\begin{array}{l}\text { - Sentimientos de vergüenza. } \\
\text { - Situaciones de discriminación. } \\
\text { - Defensa de los derechos de los demás. }\end{array}$} & \multicolumn{3}{|c|}{$\begin{array}{l}\text { Presiones del grupo. } \\
\text { Acusaciones del grupo. }\end{array}$} \\
\hline $\begin{array}{l}\text { ACTIVIDADES } \\
\text { PARA EL } \\
\text { MODELADO }\end{array}$ & \multicolumn{4}{|c|}{$\begin{array}{l}\text { 1.Queja por la difusión de un falso rumor. } \\
\text { 2.Quejas por el reparto de tareas en la casa. } \\
\text { 3.Quejas de los vecinos. } \\
\text { 4.Quejas con los amigos. }\end{array}$} & \multicolumn{4}{|c|}{$\begin{array}{l}\text { 1. Desvelamiento de secretos. } \\
\text { 2. Descubrir a alguien en una mentira. } \\
\text { 3. Marginación de una persona. } \\
\text { 4. Defensa de un amigo ante los padres. } \\
\text { 5. Defensa de un amigo ante otros amigos. }\end{array}$} & \multicolumn{3}{|c|}{$\begin{array}{l}\text { 1. Presiones familiares. } \\
\text { 2. Presiones de amigos. } \\
\text { 3. Presiones de los superiores. } \\
\text { 4. Acusaciones de los vecinos. } \\
\text { 5. Acusaciones de extraños. } \\
\end{array}$} \\
\hline METODOLOGÍA & \multicolumn{11}{|c|}{$\begin{array}{l}\text { La metodología es propia de un programa de habilidades sociales, que consta de los siguientes pasos: 1)- Instrucción verbal; 2)- Modelado, 3)- Ensayo y } \\
\text { práctica; 4)- Evaluación y feed-back; 5)- Recapitulación de la sesión; 6)- Tareas para casa. }\end{array}$} \\
\hline TEMPORALIZACIÓN & $1 / 2 \mathrm{~h}$. & $1 / 2 \mathrm{~h}$. & descanso & \begin{tabular}{|l|l}
$1 / 2 \mathrm{~h}$. & $1 / 2 \mathrm{~h}$. \\
\end{tabular} & $1 / 2 \mathrm{~h}$. & $1 / 2 \mathrm{~h}$. & descanso & \begin{tabular}{|l|l}
$1 / 2 h$. & $1 / 2 h$. \\
\end{tabular} & \begin{tabular}{l|l}
$1 / 2 \mathrm{~h}$. & $1 / 2 \mathrm{~h}$. \\
\end{tabular} & descanso & \begin{tabular}{l|l}
$1 / 2$ h. & $1 / 2 \mathrm{~h}$. \\
\end{tabular} \\
\hline
\end{tabular}




\section{BLOQUE 6: “ HABILIDADES DE PLANIFICACIÓN"}

\begin{tabular}{|c|c|c|c|c|c|c|c|c|c|c|}
\hline SESIONES & \multicolumn{5}{|c|}{1} & \multicolumn{5}{|c|}{2} \\
\hline $\begin{array}{l}\text { OBJETIVO } \\
\text { GENERAL }\end{array}$ & \multicolumn{10}{|c|}{$\begin{array}{l}\text { Enseñar a solucionar, de forma constructiva y positiva, los problemas interpersonales que se les platea en su relación con otras } \\
\text { personas. }\end{array}$} \\
\hline $\begin{array}{l}\text { OBJETIVOS } \\
\text { ESPECÍFICOS }\end{array}$ & \multicolumn{5}{|c|}{$\begin{array}{l}\text { Aprender a establecer objetivos. } \\
\text { Proporcionar estrategias para la toma de decisiones. }\end{array}$} & \multicolumn{5}{|c|}{$\begin{array}{l}\text { - Ayudar a resolver problemas. } \\
\text { - Analizar las distintas alternativas ante un problema y recoger } \\
\text { información de distintas fuentes. } \\
\text { - Reflexionar sobre las propias habilidades y capacidades ante los } \\
\text { problemas. }\end{array}$} \\
\hline CONTENIDOS & \multicolumn{5}{|c|}{$\begin{array}{l}\text { Establecimiento de objetivos. } \\
\text {. Toma de decisiones. }\end{array}$} & \multicolumn{5}{|c|}{$\begin{array}{l}\text { - Resolución de problemas. } \\
\text { - Alternativas ante un problema. } \\
\text { - Reflexión sobre las propias capacidades y habilidades. }\end{array}$} \\
\hline $\begin{array}{l}\text { ACTIVIDADES } \\
\text { PARA EL } \\
\text { MODELADO }\end{array}$ & \multicolumn{5}{|c|}{$\begin{array}{l}\text { 1)Establecimiento de objetivos para buscar trabajo. } \\
\text { 2)Establecimiento de objetivos para comprar una casa. } \\
\text { 3) Toma de decisiones económicas. } \\
\text { 4)Toma de decisiones de cara a independizarse }\end{array}$} & \multicolumn{5}{|c|}{ 1)Resolución de problemas propuestos por los orientadores. } \\
\hline TEMPORALIZACIÓN & $1 / 2 \mathrm{~h}$. & $1 / 2 h$. & descanso & $1 / 2 \mathrm{~h}$. & $1 / 2 h$. & $1 / 2 \mathrm{~h}$. & $1 / 2 \mathrm{~h}$. & descanso & $1 / 2 h$. & $1 / 2 \mathrm{~h}$. \\
\hline
\end{tabular}




\section{ENTRENAMIENTO EN TÉCNICAS DE BÚSQUEDA DE EMPLEO}

\section{BLOQUE 1: "¿QUÉ QUIERO HACER?"}

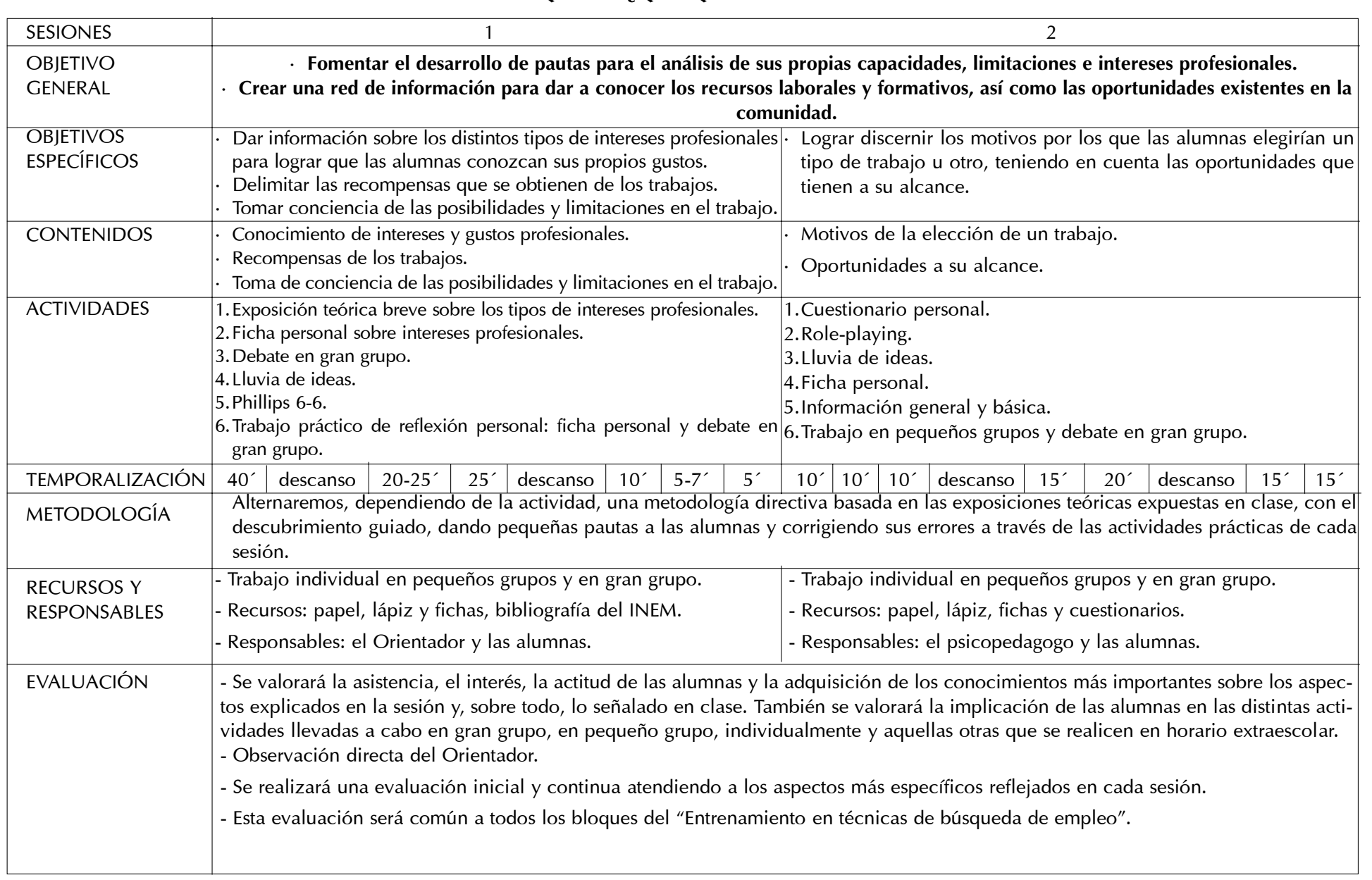




\section{BLOQUE 2: "ENTONCES, ¿QUÉ DEBO HACER?"}

\begin{tabular}{|c|c|c|c|c|c|c|c|c|c|c|}
\hline SESIONES & \multicolumn{3}{|c|}{1} & \multicolumn{3}{|c|}{2} & \multicolumn{4}{|c|}{3} \\
\hline $\begin{array}{l}\text { OBJETIVO } \\
\text { GENERAL }\end{array}$ & \multicolumn{10}{|c|}{$\begin{array}{l}\text { - Informar de las técnicas y métodos de búsqueda de empleo } \\
\text { Potenciar la fijación de metas en relación a la búsqueda de posibles empleos. }\end{array}$} \\
\hline $\begin{array}{l}\text { OBJETIVOS } \\
\text { ESPECÍFICOS }\end{array}$ & \multicolumn{3}{|c|}{$\begin{array}{l}\text { Incitar a la alumnas a que hagan un balan- } \\
\text { ce sobre lo que saben hacer, estudios, } \\
\text { experiencia, etc. para comenzar a trabajar. }\end{array}$} & \multicolumn{3}{|c|}{$\begin{array}{l}\text { Fomentar el interés de las alumnas por } \\
\text { conocer los distintos lugares donde infor- } \\
\text { marse sobre cuestiones laborales. }\end{array}$} & \multicolumn{4}{|c|}{$\begin{array}{l}\text { Lograr la profesionalización de las alum- } \\
\text { nas en el campo laboral y la consecución } \\
\text { de las metas que se han propuesto. }\end{array}$} \\
\hline CONTENIDOS & \multicolumn{3}{|c|}{$\begin{array}{l}\text { Realización del siguiente balance: qué sé } \\
\text { hacer, qué conozco, qué se me da bien, } \\
\text { qué me gusta... }\end{array}$} & \multicolumn{3}{|c|}{$\begin{array}{l}\text { Conocimiento de los lugares de informa- } \\
\text { ción sobre cuestiones laborales. }\end{array}$} & \multicolumn{4}{|c|}{$\begin{array}{l}\text { Profesionalización en el campo laboral. } \\
\text {. Logro de metas. }\end{array}$} \\
\hline TEMPORALIZACIÓN & $10^{\prime}$ & $20^{\prime}$ descanso & $20^{\prime}$ descanso $20-25^{\prime}$ & $20^{\prime}$ & $15^{\prime}$ & resto de la clase & $30^{\prime}$ descanso $10^{\prime}$ & $15^{\prime}$ descanso & $10^{\prime}$ & $15^{\prime}$ \\
\hline
\end{tabular}




\section{BLOQUE 3: “ME PONGO A BUSCAR EMPLEO"}

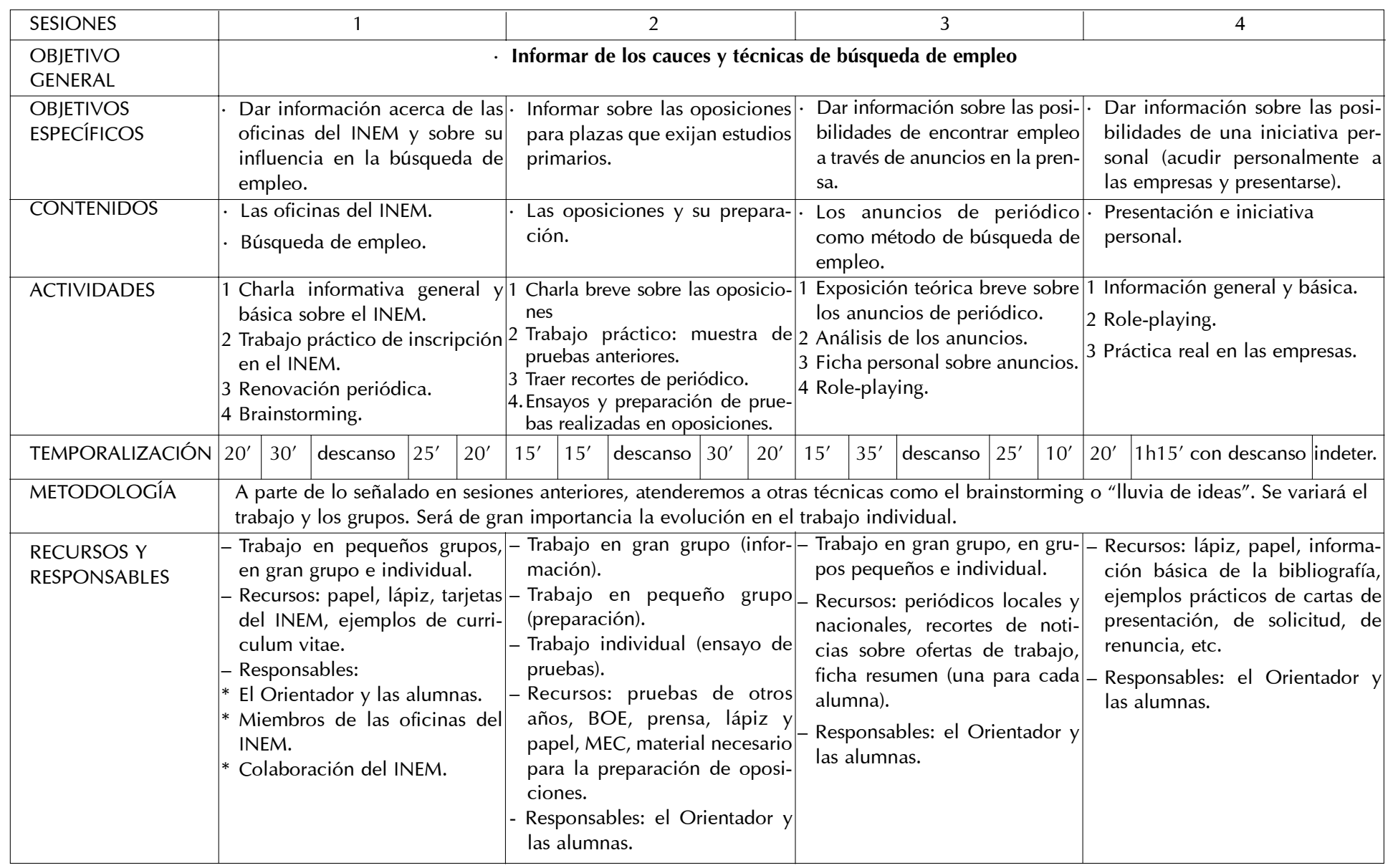




\section{BLOQUE 3: "ME PONGO A BUSCAR EMPLEO"}

\begin{tabular}{|c|c|c|c|}
\hline SESIONES & \multicolumn{3}{|c|}{5} \\
\hline $\begin{array}{l}\text { OBJETIVO } \\
\text { GENERAL }\end{array}$ & \multicolumn{3}{|c|}{ Informar de los cauces y técnicas de búsqueda de empleo } \\
\hline $\begin{array}{l}\text { OBJETIVOS } \\
\text { ESPECÍFICOS }\end{array}$ & \multicolumn{3}{|c|}{ Informar de la posibilidad de encontrar empleo mediante el uso de anuncios personales en la prensa } \\
\hline CONTENIDOS & \multicolumn{3}{|c|}{$\begin{array}{l}\text { - Adquisición de información básica sobre los anuncios de demandantes de empleo. } \\
\text { - Iniciativa personal de las alumnas para anunciarse. }\end{array}$} \\
\hline ACTIVIDADES & \multicolumn{3}{|c|}{$\begin{array}{l}\text { 1. Información general con ejemplos. } \\
\text { 2. Trabajar con anuncios de prensa } \\
\text { 3. Colocar anuncios en la calle y responder a anuncios de prensa. } \\
\text { 4. Elaborar un banco de profesiones u ocupaciones próximas a las posibilidades reales de nuestras alumnas. }\end{array}$} \\
\hline TEMPORALIZACIÓN & $45^{\prime}$ & descanso & 1h $15^{\prime}$ y descansointermedio \\
\hline $\begin{array}{l}\text { RECURSOS Y } \\
\text { RESPONSABLES }\end{array}$ & \multicolumn{3}{|c|}{$\begin{array}{l}\text { - Trabajo en pequeños grupos, en gran grupo e individual. } \\
\text { - Recursos: papel, lápiz, periódicos, ejemplos traídos de tiendas, tablones de anuncios... } \\
\text { - Responsables: el Orientador y las alumnas. }\end{array}$} \\
\hline
\end{tabular}




\section{BLOQUE 4: “CONTINÚO HASTA ENCONTRARLO"}

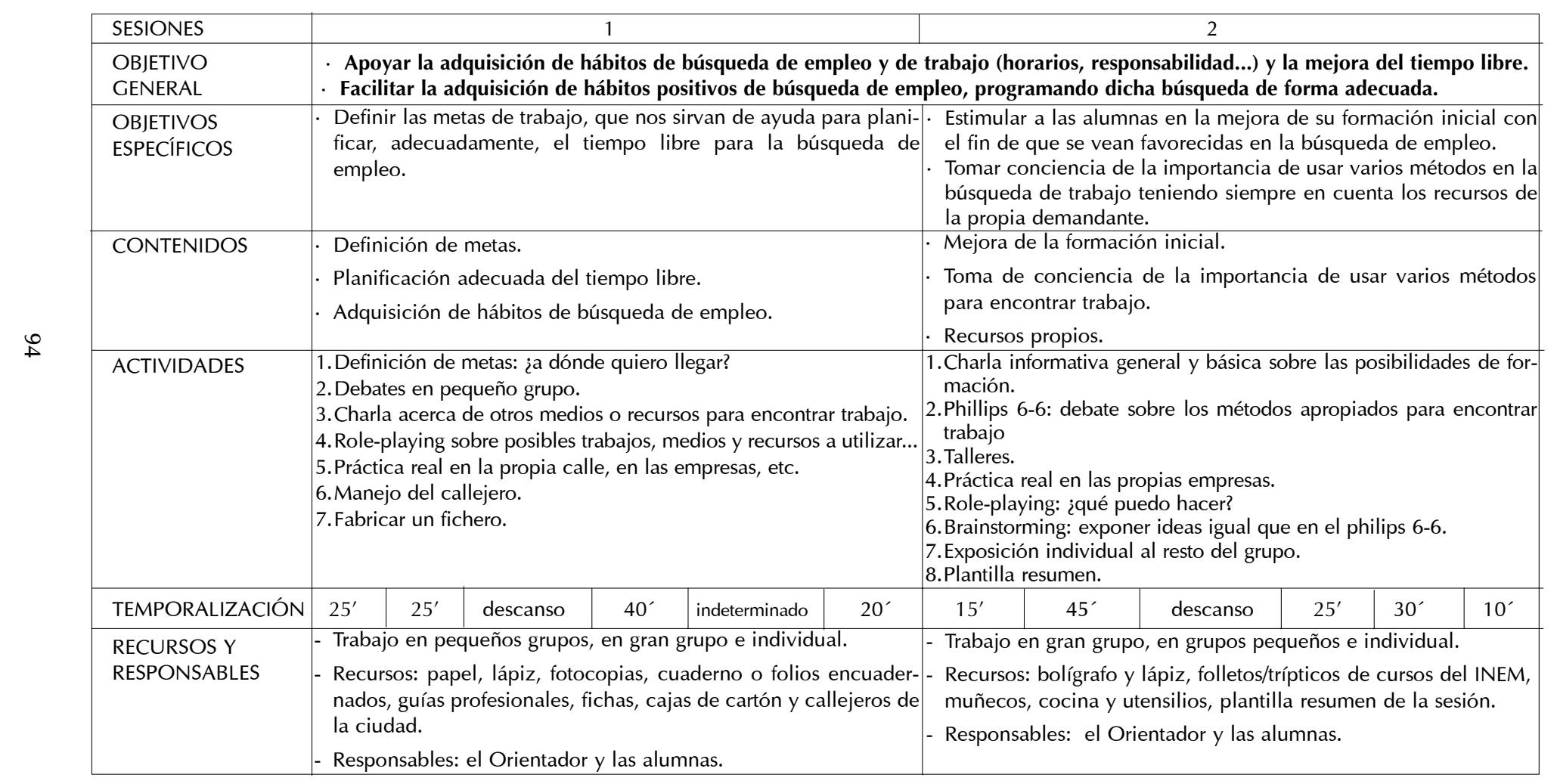


BLOQUE 5: "LA SELECCIÓN"

\begin{tabular}{|c|c|c|c|c|c|c|c|c|c|c|c|c|c|}
\hline SESIONES & \multicolumn{3}{|c|}{1} & \multicolumn{3}{|c|}{2} & \multicolumn{3}{|c|}{3} & \multicolumn{4}{|c|}{4} \\
\hline $\begin{array}{l}\text { OBJETIVO } \\
\text { GENERAL }\end{array}$ & \multicolumn{13}{|c|}{$\begin{array}{l}\text { - Informar de los cauces y técnicas de búsqueda de empleo } \\
\text { Fomentar el desarrollo de pautas para el análisis de sus propias capacidades, limitaciones e intereses profesionales. }\end{array}$} \\
\hline $\begin{array}{l}\text { OBJETIVOS } \\
\text { ESPECÍFICOS }\end{array}$ & \multicolumn{3}{|c|}{$\begin{array}{l}\text { Informar sobre el perfil profe- } \\
\text { sional más valorado a la hora } \\
\text { de buscar trabajo. } \\
\text { Ayudar a reflexionar sobre las } \\
\text { competencias y aptitudes per- } \\
\text { sonales. }\end{array}$} & \multicolumn{3}{|c|}{$\begin{array}{l}\text { Distinguir entre diversos tipos } \\
\text { de cartas de presentación. } \\
\text { Conocer los formulismos utili- } \\
\text { zados en una carta de presen- } \\
\text { tación. }\end{array}$} & \multicolumn{3}{|c|}{$\begin{array}{l}\text { Aprender a redactar una carta } \\
\text { de presentación. } \\
\text { Conocer la importancia del } \\
\text { curriculum vitae como carta de } \\
\text { identidad. } \\
\text { Conocer los distintos tipos de } \\
\text { curriculum. Aprender a redac- } \\
\text { tar un curriculum. }\end{array}$} & \multicolumn{4}{|c|}{$\begin{array}{l}\text { Conocer la entrevista como pro- } \\
\text { ceso de selección. } \\
\text { Distinguir entre una entrevista } \\
\text { informal y un a entrevista formal. } \\
\text { Distinguir las partes de la entre- } \\
\text { vista. } \\
\text { Aprender el uso del lenguaje ver- } \\
\text { bal y no verbal en la entrevista. }\end{array}$} \\
\hline CONTENIDOS & \multicolumn{3}{|c|}{$\begin{array}{l}\text { Conocimiento del perfil profe- } \\
\text { sional más valorado. } \\
\text { Reflexión sobre aptitudes y } \\
\text { competencias personales. }\end{array}$} & \multicolumn{3}{|c|}{$\begin{array}{l}\text { - Tipos de cartas de presentación. } \\
\text { - Formulismos de una carta de } \\
\text { presentación. } \\
\text { - Redacción de una carta de pre- } \\
\text { sentación. }\end{array}$} & \multicolumn{3}{|c|}{$\begin{array}{l}\text { Importancia del curriculum. } \\
\text { Tipos de curriculum. } \\
\text { Redacción del curriculum. }\end{array}$} & \multicolumn{4}{|c|}{$\begin{array}{l}\text { - Conocimiento de la entrevista } \\
\text { como proceso de selección. } \\
\text { - Tipos de entrevista. } \\
\text { - Fases de la entrevista. } \\
\text { - Lenguaje verbal y no verbal en } \\
\text { la entrevista. }\end{array}$} \\
\hline ACTIVIDADES & \multicolumn{3}{|c|}{$\begin{array}{l}1 \text { Estudiar en el anuncio el can- } \\
\text { didato ideal. } \\
2 \text { Confeccionar el propio perfil } \\
\text { profesional. }\end{array}$} & \multicolumn{3}{|c|}{$\begin{array}{l}1 \text { Carta de presentación. } \\
2 \text { Redactar una carta de presen- } \\
\text { tación. } \\
3 \text { Seleccción de personal. }\end{array}$} & \multicolumn{3}{|c|}{\begin{tabular}{|l|}
1 El curriculum vitae. \\
2 Selección del curriculum vitae. \\
3 Redacción del curriculum \\
vitae.
\end{tabular}} & \multicolumn{4}{|c|}{$\begin{array}{l}1 \text { Estudiar la entrevista. } \\
2 \text { Analizar las preguntas de una } \\
\text { entrevista. } \\
3 \text { Estudiar el lenguaje verbal y no } \\
\text { verbal en una entrevista. }\end{array}$} \\
\hline TEMPORALIZACIÓN & $1 \mathrm{~h}$ & descanso & $1 \mathrm{~h}$ & \begin{tabular}{l|l|}
$1 \mathrm{~h}$ & descanso \\
\end{tabular} & $1 / 2 \mathrm{~h}$ & $1 / 2 \mathrm{~h}$ & $1 / 2 \mathrm{~h}$ & \begin{tabular}{l|l}
$1 / 2 \mathrm{~h}$ & descanso
\end{tabular} & $1 \mathrm{~h}$ & $1 / 2 h$ & $1 / 2 h$ & descanso & $1 \mathrm{~h}$ \\
\hline RECURSOS & \multicolumn{3}{|c|}{$\begin{array}{l}1 \text { Periódicos, cartulina, tijeras y } \\
\text { pegamento. } \\
2 \text { Papel y lápiz. }\end{array}$} & \multicolumn{3}{|c|}{$\begin{array}{l}1 \text { Modelo de carta de presenta- } \\
\text { ción. } \\
2 \text { Papel y bolígrafo. }\end{array}$} & $\begin{array}{r}1 \text { Mod } \\
2 \text { Doc } \\
\text { reale } \\
3 \text { Pape }\end{array}$ & $\begin{array}{l}\text { lo de currículum } \\
\text { mentos sobre su } \\
\text { y bolígrafo. }\end{array}$ & estos & \multicolumn{4}{|c|}{$\begin{array}{l}1 \text { Pizarra. } \\
2 \text { Papel y bolígrafo. } \\
3 \text { Pizarra. }\end{array}$} \\
\hline
\end{tabular}




\section{BLOQUE 5: “LA SELECCIÓN"}

\begin{tabular}{|c|c|c|c|c|c|c|}
\hline SESIONES & \multicolumn{3}{|c|}{5} & \multicolumn{3}{|c|}{6} \\
\hline OBJETIVO & \multicolumn{6}{|c|}{ Informar de los cauces y técnicas de búsqueda de empleo } \\
\hline GENERAL & \multicolumn{6}{|c|}{ Fomentar el desarrollo de pautas para el análisis de sus propias capacidades, limitaciones e intereses profesionales. } \\
\hline $\begin{array}{l}\text { OBJETIVOS } \\
\text { ESPECÍFICOS }\end{array}$ & \multicolumn{3}{|c|}{$\begin{array}{l}\text { Vivir una situación de entrevista laboral. } \\
\text { Analizar los propios recursos personales. }\end{array}$} & \multicolumn{3}{|c|}{$\begin{array}{l}\text { - Conocer las pruebas estandarizadas para la selección de candida- } \\
\text { tos. } \\
\text { - Familiarizarse con los tests como pruebas de selección de personal } \\
\text { - Vivir una situación de aplicación de test. }\end{array}$} \\
\hline CONTENIDOS & \multicolumn{3}{|c|}{$\begin{array}{l}\text { Distintas situación de entrevista laboral. } \\
\text { Análisis de los recursos personales. }\end{array}$} & \multicolumn{3}{|c|}{$\begin{array}{l}\text { Conocimiento de pruebas estandarizadas de selección. } \\
\text { Aplicación de tests. }\end{array}$} \\
\hline ACTIVIDADES & \multicolumn{3}{|c|}{$\begin{array}{l}1 \text { Grabación en vídeo de entrevistas simuladas. } \\
2 \text { Análisis de las entrevistas. }\end{array}$} & \multicolumn{3}{|c|}{$\begin{array}{l}1 \text { Los tests como pruebas de selección. } \\
2 \text { Aplicación de tests. }\end{array}$} \\
\hline TEMPORALIZACIÓN & $1 \mathrm{~h}$ & descanso & $1 \mathrm{~h}$ & $1 \mathrm{~h}$ & descanso & $1 \mathrm{~h}$ \\
\hline RECURSOS & \multicolumn{3}{|c|}{$\begin{array}{l}1 \text { Cámara de vídeo. } \\
2 \text { Pizarra. }\end{array}$} & \multicolumn{3}{|c|}{ 1) y 2) Modelos de tests. } \\
\hline
\end{tabular}




\section{BLOQUE 6: “EN TU NUEVO TRABAJO”}

\begin{tabular}{|c|c|c|c|c|c|c|c|c|}
\hline SESIONES & \multicolumn{2}{|l|}{1} & \multicolumn{3}{|c|}{2} & \multicolumn{3}{|c|}{3} \\
\hline $\begin{array}{l}\text { OBJETIVO } \\
\text { GENERAL }\end{array}$ & \multicolumn{8}{|c|}{$\begin{array}{l}\text { Apoyar la adquisición de hábitos de trabajo (horarios, responsabilidad, permanencia) } \\
\text {. Potenciar la fijación de metas con relación a la búsqueda de empleo. } \\
\text { Mejorar el conocimiento sobre los contratos de trabajo y los derechos de los trabajadores. }\end{array}$} \\
\hline $\begin{array}{l}\text { OBJETIVOS } \\
\text { ESPECÍFICOS }\end{array}$ & \multicolumn{2}{|c|}{$\begin{array}{l}\text { Conocer los distintos tipos de contrato. } \\
\text { Informar sobre la documentación que } \\
\text { acompaña a un contrato de trabajo. } \\
\text { Dar a conocer las implicaciones laborales } \\
\text { de cada uno de los tipos de contrato. }\end{array}$} & \multicolumn{3}{|c|}{$\begin{array}{l}\text { Conocer los principales derechos y debe- } \\
\text { res de los trabajadores. } \\
\text { Informar sobre las posibilidades de presta- } \\
\text { ción por desempleo. }\end{array}$} & \multicolumn{3}{|c|}{$\begin{array}{l}\text { - Aprender a utilizar estrategias personales } \\
\text { para la defensa de los derechos laborales. }\end{array}$} \\
\hline CONTENIDOS & \multicolumn{2}{|c|}{$\begin{array}{l}\text { - Conocimiento de distintos tipos de contrato. } \\
\text { - Información sobre distintos documentos } \\
\text { laborales. } \\
\text {. Conocimiento de las implicaciones labora- } \\
\text { les de los diferentes contratos. } \\
\text {. Derechos y deberes de los trabajadores. }\end{array}$} & \multicolumn{3}{|c|}{$\begin{array}{l}\text { Posibilidades de prestación por desempleo. } \\
\text { Utilización de estrategias personales para } \\
\text { la defensa de derechos laborales. }\end{array}$} & \multicolumn{3}{|c|}{$\begin{array}{l}\text { - Utilización de estrategias personales para } \\
\text { la defensa de los derechos laborales. }\end{array}$} \\
\hline ACTIVIDADES & \multicolumn{2}{|c|}{$\begin{array}{l}1 \text { Estudiar los distintos tipos de contrato que } \\
\text { existen y la documentación que les acom- } \\
\text { paña. } \\
2 \text { Debate sobre los derechos y deberes de los } \\
\text { trabajadores: cuáles creen y cuáles son. }\end{array}$} & \multicolumn{3}{|c|}{$\begin{array}{l}\text { 1.Estudio de casos a través de la prensa. } \\
2 \text { Charla profesional a cargo de un técnico } \\
\text { del INEM. }\end{array}$} & \multicolumn{3}{|c|}{$\begin{array}{l}1 \text { Estudio de casos. } \\
2 \text { Dramatización. }\end{array}$} \\
\hline TEMPORALIZACIÓN & descanso & $1 \mathrm{~h}$ & $1 \mathrm{~h}$ & descanso & $1 \mathrm{~h}$ & $1 \mathrm{~h}$ & descanso & $1 \mathrm{~h}$ \\
\hline METODOLOGÍA & \multicolumn{8}{|c|}{$\begin{array}{l}\text { Vamos a alternar, dependiendo de la actividad, una metodología directiva basada en las exposiciones teóricas en clase, con el descu- } \\
\text { brimiento guiado, en la que damos pequeñas pautas a las alumnas y corregimos sus errores. }\end{array}$} \\
\hline $\begin{array}{l}\text { RECURSOS Y } \\
\text { RESPONSABLES }\end{array}$ & \multicolumn{2}{|c|}{$\begin{array}{l}\text { - Recursos: manejo de diferentes tipos de } \\
\text { documentación, periódicos, papel y bolí- } \\
\text { grafo. } \\
\text { - Responsables: el Orientador y las alumnas. }\end{array}$} & \multicolumn{3}{|c|}{$\begin{array}{l}\text { Recursos: Distintos modelos de casos rea- } \\
\text { les. } \\
\text { - Responsables: Profesional del INEM. }\end{array}$} & \multicolumn{3}{|c|}{$\begin{array}{l}\text { - Recursos: Papeles para la dramatización } \\
\text { del tema. } \\
\text { - Responsables: el Orientador y las alumnas. }\end{array}$} \\
\hline EVALUACIÓN & \multicolumn{8}{|c|}{$\begin{array}{l}\text { Se valorará la asistencia, el interés y la actitud de las alumnas, así como la adquisición de los conocimientos más importantes sobre } \\
\text { los que se las está informando. Se valorará la implicación de las alumnas en las actividades individuales, grupales, escolares y extra- } \\
\text { escolares. }\end{array}$} \\
\hline
\end{tabular}


BLOQUE 7: “SESIONES DE EVALUACIÓN DE LOS BLOQUES ANTERIORES"

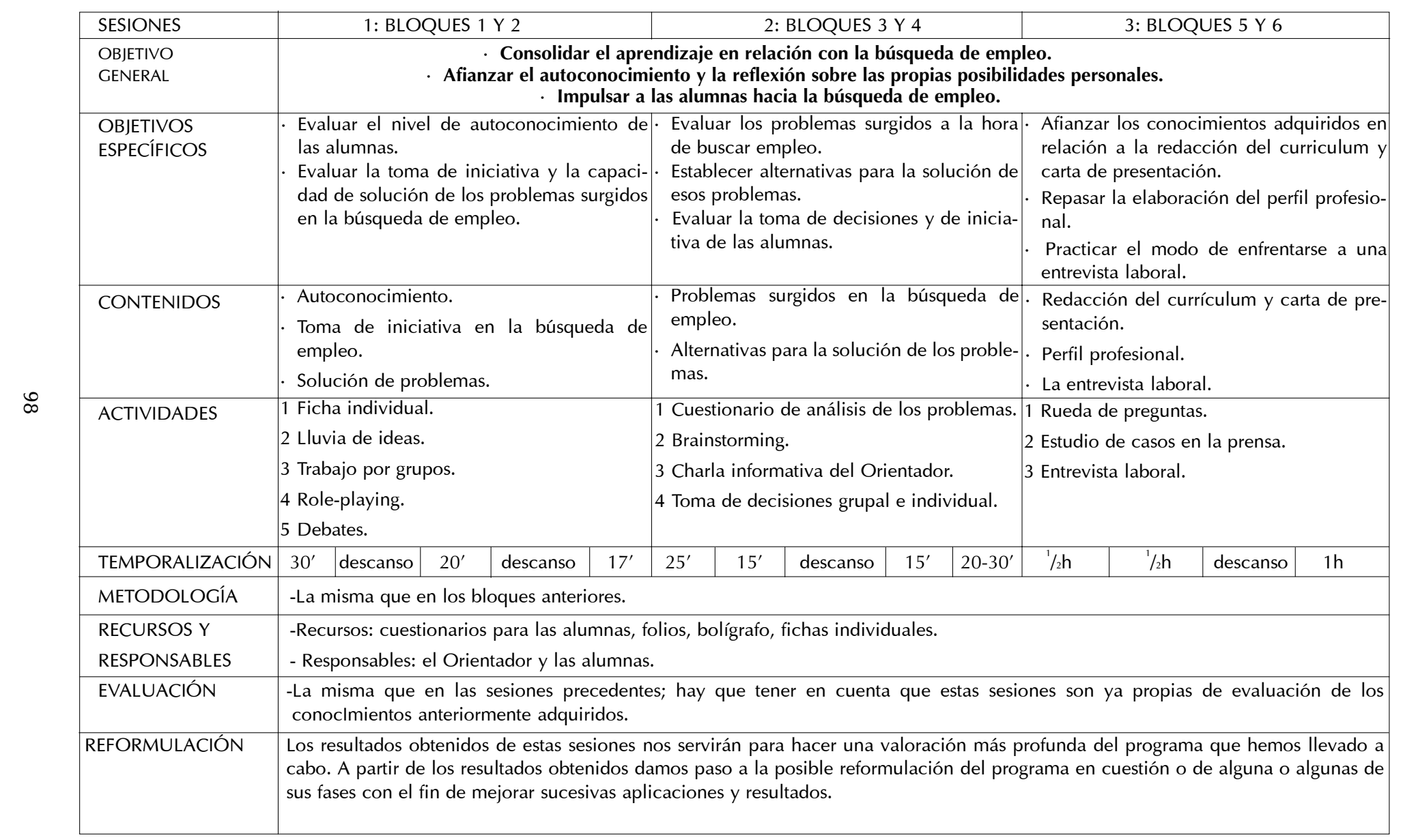


DISEÑO DE UN PROGRAMA DE ORIENTACIÓN ACADÉMICA Y PROFESIONAL PARA LAS MUJERES

\section{Bibliografía}

CEBOLLADA, FÉLIX F. (1998). Mujer trabajadora, se rompe el silencio. En Noticias Obreras, №. 151, pp. 19-25.

ENCICLOPEDIA BIOGRÁFICA DE LA MUJER. (1967). Tomos I y II. Barcelona: Ediciones Garriga.

GALLÉN, A. (1996). Trabajando con mujeres. Habilidades sociales y cognitivas. Madrid: Cáritas.

GOLDSTEIN, A.(1989). Habilidades sociales y autocontrol en la adolescencia. Barcelona: Martínez Roca.

INSTITUTO DE LA MUJER. (1996). Plan MABEM. Madrid: Ministerio de Asuntos Sociales.

JUNTA DE CASTILLA Y LEÓN. (1998). Resumen general de estudios sobre la prostitución femenina en Castilla y León. Valladolid: Asé-psyké.

MONJAS CASARES, I. (1993). Programa de enseñanza de habilidades de interacción social para niños y niñas en edad escolar. Valladolid: Casares.

KNISSLER, M. (1993). El imperio de los sentidos. En Muy Especial, no 13. Madrid.

ONU, MEC, Instituto de la Mujer. (1998). Causas de la prostitución y estrategia contra el proxenetismo. Madrid: El mismo. Serie 4.

SOLÉ, C. (1994). La mujer inmigrante. Madrid: Instituto de la Mujer.

CONSEJERÍA DE SERVICIOS SOCIALES. (2000). Prostitución y tráfico de mujeres con fines de explotación sexual. Simposio Internacional. Madrid: El mismo.

VASALLO, M.; LOPSZYC, C. y BARRANCOS, D. (1999). La prostitución. En Feminaria, no 22/23. Madrid. 